\title{
KAJIAN IMPLEMENTASI KEBIJAKAN DALAM PENGELOLAAN BEBERAPA HUTAN LINDUNG DI KALIMANTAN TIMUR
}

\author{
(Study on Implementation of the Policies in the \\ Management of Some Protection Forests in East Kalimantan)
}

\author{
Oleh/by: \\ Faiqotul Falah ${ }^{1)}$
}

\begin{abstract}
This paper studied the compatibility between the policies at national and regional levels with management activities in some protected forests in East Kalimantan, namely Sungai Wain Protection Forest (HLSW), Wehea Forest (HW), Gunung Lumut Protection Forest (HLGL), and Gunung Beratus Protection Forest (HLGB).

According to PP No 62/1998, the government at regency and city levels hold the protection forests management authority, with the consequence that they also bold the authority of management institution establishment. Colaborative management boards had been established in HLSW and HW. In HLGL, the role of management institution is operated by a Management Working Group. While in HLGB, a Working Group working on the preparation of Management Institution had been founded. In HLSW, HW, HLGL, and HLGB, the main issue that motivated the founding of management institution was the conservation of endangered fauna and their habitats. The incompatibility between the policies at the national and regency levels occured in $H W$. Although $H W$ still holds a function as a production forest, by designation, the local government has formed a Wehea Protection Forest Management Board.

In forest areas which already had Management Board, forest protection is implemented more efectively by the establishment of a safeguard team that involved local people. And so the forest use activities have been more controllable by the issuance of government and custom regulations regarding forest uses and the permit procedures. But there is still no regulation that obliges water consumer to pay fee for the incentive of protection forest management.
\end{abstract}

Keywords:policy, protection forest management, management institution

\begin{abstract}
ABSTRAK
Tulisan ini bertujuan mengkaji kesesuaian antara kebijakan di tingkat pusat dan di daerah dengan kegiatan pengelolaan beberapa hutan lindung di Kalimantan Timur, yaitu Hutan Lindung Sungai Wain (HLSW), Hutan Wehea (HW), Hutan Lindung Gunung Lumut (HLGL), dan Hutan Lindung Gunung Beratus (HLGB).

Berdasarkan PP No 62/1998, kewenangan pengelolaan hutan lindung berada pada pemerintah kabupaten/kota sehingga pembentukan lembaga pengelola hutan lindung juga merupakan wewenang mereka. Lembaga pengelola kolaboratif telah dibentuk di HLSW dan HW. Di HLGL peran lembaga pengelola dijalankan oleh Kelompok Kerja Pengelola, sedang di HLGB
\end{abstract}

\footnotetext{
${ }^{1}$ Peneliti pada Balai Penelitian Teknologi Pembenihan Samboja, Kalimantan Timur.
} 


\section{J umal AnalisisKedijakanKehutanan \\ Vo. 4No. 1, Mare 2007: 1- 19}

baru sampai pada tahap pembentukan Kelompok Kerja Penyiapan Lembaga Pengelola. Di HLSW, HW, dan HLGB, isu utama yang mendorong proses pembentukan lembaga pengelola adalah pelestarian fauna langka dan habitatnya. Ketidaksesuaian antara kebijakan pemerintah pusat dengan pemerintah daerah terjadi di HW yang meskipun berstatus hutan produksi, namun pemerintah kabupaten setempat telah membentuk Badan Pengelola Hutan Lindung Wehea.

Pada kawasan hutan yang telah mempunyai Badan Pengelola, pelaksanaan kegiatan perlindungan hutan lebih efektif dengan dibentuknya tim pengamanan yang melibatkan masyarakat. Demikian juga kegiatan pemanfaatan hutan lebih terarah dengan diterbitkannya kebijakan pemerintah daerah dan lembaga adat mengenai pemanfaatan kawasan hutan dan perizinannya. Namun belum ada Peraturan Perundang-undangan yang mencantumkan kewajiban konsumen membayar insentif pemakaian air untuk kepentingan pengelolaan hutan lindung.

Kata kunci: Kebijakan, pengelolaan hutan lindung, lembaga pengelola

\section{PENDAHULUAN}

Hutan lindung adalah kawasan hutan yang mempunyai fungsi pokok sebagai perlindungan sistem penyangga kehidupan untuk mengatur tata air, mencegah banjir, mengendalikan erosi, dan memelihara kesuburan tanah (UU No 41 Tahun 1999). Luas keseluruhan hutan lindung di Indonesia sampai dengan tahun 2002 adalah seluas 20.772.591ha atau sekitar 22,15\% dari keseluruhan luas hutan di Indonesia. Pada tahun 2004 luas hutan lindung di propinsi Kalimantan Timur adalah seluas 2.751.702 ha, atau 13,5\% dari keseluruhan luas kawasan hutan lindung di seluruh Indonesia, atau sekitar 19,5\% dari luas seluruh kawasan hutan daratan dan perairan di Kalimantan Timur (sumber: www.dephut.go.id, 2005).

Kebijakan pengelolaan hutan lindung juga melibatkan pemerintah pusat dan daerah. Luasan dan tata batas areal hutan lindung ditetapkan oleh pemerintah pusat melalui SK Menteri sedang penataan dan pemanfaatannya berpedoman pada Undang-Undang dan Peraturan Pemerintah. Sejak pemberlakuan otonomi daerah, sebagian urusan pemerintahan di bidang kehutanan diserahkan pada daerah, termasuk wewenang pengelolaan hutan lindung yang diserahkan pada Pemerintah Daerah Tingkat II. Sedangkan pengelolaan hutan lindung yang berada dalam kawasan Taman Hutan Raya (Tahura) diserahkan pada Pemerintah Daerah Tingkat I (PP No 62 Tahun 1998).

Tulisan ini bertujuan mengkaji kesesuaian antara kebijakan yang berlaku di tingkat pusat dan daerah tingkat II pada kegiatan pengelolaan di beberapa hutan lindung di propinsi Kalimantan Timur, yaitu Hutan Lindung Sungai Wain, Hutan Lindung Gunung Lumut, Hutan Lindung Gunung Beratus, dan Hutan Wehea.

\section{PENGUMPULAN DAN ANALISA DATA}

Data primer diperoleh dari hasil wawancara dengan beberapa pihak yang terlibat dalam pengelolaan masing-masing hutan lindung, sementara data sekunder diperoleh dari dokumen-dokumen terkait, meliputi peraturan perundang-undangan di tingkat pusat maupun daerah, serta laporan hasil beberapa penelitian di masing-masing hutan lindung. 
Analisa data dilakukan terhadap hasil rekapitulasi data primer dan data sekunder. Analisa isi (content analysis) dilakukan pada Peraturan Perundangan terkait. Kegiatan pengelolaan hutan lindung dianalisa secara deskriptif kualitatif. Sedangkan analisa kesesuaian implementasi dilakukan untuk mengkaji kesesuaian antara Peraturan Perundangan dengan kegiatan pengelolaan hutan lindung.

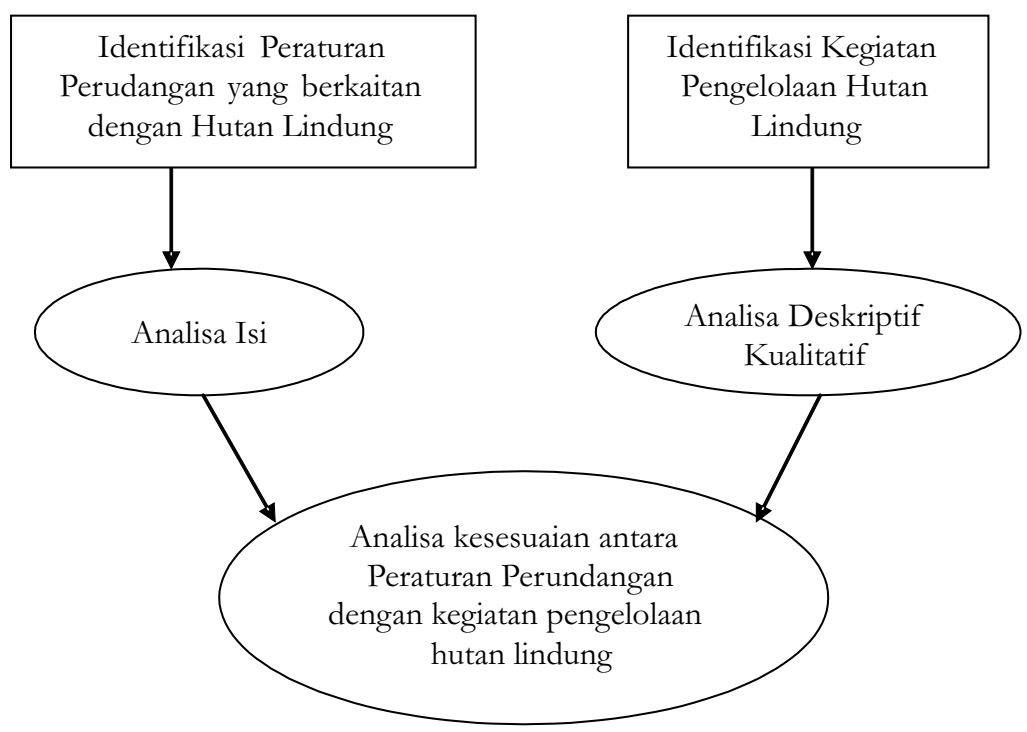

Gambar 1. Alur Penelitian

Figure 1. Research framework

\section{KEBIJAKAN PEMERINTAH PUSAT MENGENAI PENGELOLAAN HUTAN LINDUNG}

Kebijakan adalah cara dan tindakan pemerintah untuk mengatasi masalah pembangunan atau mencapai tujuan pembangunan tertentu dengan mengeluarkan keputusan, strategi, perencanaan, maupun implementasinya di lapangan dengan menggunakan instrumen-instrumen tertentu. (Djogo, Sunaryo, Suharjito dan Sirait, 2003)

Kebijakan meliputi berbagai peraturan yang berlaku baik di tingkat pusat maupun daerah. Peraturan Daerah harus mengacu kepada Peraturan Perundangan yang lebih tinggi. Adanya pandangan bahwa Peraturan Daerah (Perda) memiliki kedudukan hukum yang lebih tinggi daripada Peraturan Menteri tidak dapat diterima sepanjang mengacu kepada peraturan perundang-undangan yang lebih tinggi (Darusman \& Nurrochmat, 2005).

Kebijakan yang dilaksanakan oleh pengelola hutan lindung seyogyanya mengacu pada kebijakan di tingkat pusat maupun daerah. Beberapa peraturan perundangan pusat yang berkaitan langsung dengan pengelolaan hutan lindung dapat dilihat dalam lampiran (tabel 4). 


\section{J umal AnalisisKedijakanKedutanan}

Vo. 4No. 1, Mare 2007: 1- 19

\section{A. Kewenangan Pengelolaan Hutan Lindung}

PP 34 Tahun 2002 pasal 3 menyebutkan bahwa kegiatan tata hutan dan penyusunan rencana pengelolaan hutan, pemanfaatan hutan dan penggunaan kawasan hutan menjadi kewenangan Pemerintah atau Pemerintah Daerah. Sebelumnya dalam PP 62 Tahun 1998 pasal 5 disebutkan bahwa kepada Daerah Tingkat II diserahkan sebagian urusan pemerintahan di bidang kehutanan, antara lain meliputi pengelolaan hutan lindung.

Dalam PP No 25 Tahun 2000 disebutkan bahwa kewenangan Propinsi sebagai Daerah Otonom mencakup kewenangan dalam bidang pemerintahan yang bersifat lintas Kabupaten/Kota. Bila kawasan hutan lindung terletak pada lebih dari satu wilayah kabupaten/kota, maka kewenangan berada pada Pemerintah Propinsi. Kewenangan pemerintah propinsi juga meliputi pedoman penyelenggaraan penunjukan dan pengamanan batas hutan produksi dan hutan lindung, serta Pedoman penyelenggaraan tata batas hutan, rekonstruksi dan penataan batas kawasan hutan produksi dan hutan lindung.

Karena kewenangan pengelola hutan lindung berada di tangan pemerintah kabupaten/kota, maka pembentukan lembaga pengelola hutan lindung juga merupakan wewenang pemerintah kabupaten/kota, dan seyogyanya didasari oleh SK dari pemerintah daerah sebagai payung hukumnya.

Dalam PP No 62/1998 pasal 6 (5) disebutkan bahwa urusan pengelolaan hutan lindung tersebut mencakup kegiatan pemancangan batas, pemeliharaan batas, mempertahankan luas dan fungsi hutan lindung, pengendalian kebakaran, reboisasi dalam rangka rehabilitasi lahan kritis pada kawasan hutan lindung, dan pemanfaatan jasa lingkungan.

\section{B. Fungsi dan Status Hutan Lindung}

PP 44/2004 tentang Perencanaan Kehutanan pasal 24 ayat 3 (b) mencantumkan enam kriteria hutan lindung yaitu kawasan hutan yang mempunyai lereng lapangan 40 persen atau lebih, mempunyai ketinggian di atas permukaan laut 2000 meter atau lebih, kawasan dengan faktor kelas lereng, jenis tanah dan intensitas hujan, setelah masingmasing dikalikan dengan angka penimbang mempunyai jumlah nilai skor 175 atau lebih, kawasan hutan yang mempunyai tanah sangat peka terhadap erosi dengan lereng lapangan lebih dari 15 persen, kawasan yang merupakan daerah resapan air, dan kawasan hutan yang merupakan daerah perlindungan pantai.

Di satu sisi hutan lindung memiliki fungsi ekologis seperti fungsi hidrologi, konservasi tanah, kestabilan iklim, serta konservasi plasma nutfah. Di sisi lain, pada era otonomi daerah ini hutan lindung masih diharapkan sebagai sumber Pendapatan Asli Daerah (PAD) bagi daerah tingkat II, serta sumber pendapatan bagi masyarakat sekitarnya, sesuai dengan peraturan pemanfaatan hutan lindung yang tercantum dalam UU no 41 Tahun 1999 yang diatur lebih lanjut dalam PP 34 Tahun 2002. 


\section{Kegiatan dalam rangka penyelenggaraan tata batas hutan lindung}

PP No 44 Tahun 2004 tentang Perencanaan Hutan pasal 1 menyebutkan bahwa penunjukan dan penetapan kawasan Hutan merupakan wewenang pemerintah pusat. Dalam PP No 25/2000 pasal 3 kewenangan pemerintah propinsi meliputi pedoman penyelenggaraan tata batas hutan, rekonstruksi dan penataan batas kawasan hutan produksi dan hutan lindung. Sedang pada operasionalnya, Pemerintah Daerah Tingkat II mempunyai wewenang dalam penyelenggaraan tata batas hutan, rekonstruksi dan penataan batas kawasan hutan produksi dan hutan lindung sesuai Rencana Tata Ruang Kabupaten (RTRK). Dalam PP No 34 Tahun 2002 pasal 12 (2) juga disebutkan bahwa tata hutan pada hutan lindung antara lain meliputi pembagian kawasan hutan lindung dalam tiga blok, yaitu blok perlindungan, blok pemanfaatan, dan blok lainnya.

\section{Kegiatan dalam rangka perlindungan hutan}

Dalam UU 41/1999 pasal 46 dan 47, penyelenggaraan perlindungan hutan dan konservasi alam bertujuan menjaga hutan, kawasan hutan dan lingkungannya, agar fungsi lindung, fungsi konservasi, dan fungsi produksi, tercapai secara optimal dan lestari. Dalam pasal 48 disebutkan bahwa Pemerintah mengatur perlindungan hutan, baik di dalam maupun di luar kawasan hutan. Perlindungan hutan pada hutan negara dilaksanakan oleh pemerintah. Sedangkan pemegang izin pemanfaatan hutan berkewajiban melindungi hutan dalam areal kerjanya.

UU No. 7/2004 tentang Sumber Daya Air pasal 21 menyatakan bahwa perlindungan dan pelestarian sumber air beserta lingkungan keberadaannya terhadap kerusakan atau gangguan yang disebabkan oleh daya alam dan oleh tindakan manusia dilakukan melalui pemeliharaan kelangsungan fungsi resapan air dan daerah tangkapan air, rehabilitasi hutan dan lahan atau pelestarian hutan lindung, kawasan suaka alam dan kawasan pelestarian alam. Pasal 94 menyebutkan tentang ketentuan pidana bagi setiap orang yang sengaja melakukan kegiatan yang mengakibatkan rusaknya sumber air. Karena itu Undang-undang ini juga mendukung upaya pelestarian hutan lindung.

\section{Reboisasi dalam rangka rehabilitasi lahan kritis di kawasan hutan lindung}

Dalam UU 41/1999 Pasal 40 dan 41 disebutkan bahwa rehabilitasi hutan dan lahan dimaksudkan untuk memulihkan, mempertahankan, dan meningkatkan fungsi hutan dan lahan sehingga daya dukung, produktivitas, dan peranannya dalam mendukung sistem penyangga kehidupan tetap terjaga. Rehabilitasi hutan dan lahan diselenggarakan melalui kegiatan reboisasi, penghijauan, pemeliharaan, pengayaan tanaman, atau penerapan teknis konservasi tanah secara vegetatitf dan sipil teknis, pada lahan kritis dan tidak produktif. Dalam PP 62 Tahun 1998, kegiatan reboisasi dalam rangka rehabilitasi lahan kritis di kawasan hutan lindung ini merupakan salah satu wewenang pemerintah daerah tingkat II.

\section{Pemanfaatan Hutan Lindung}

UU No. 41/1999 pasal 26 yang diatur lebih lanjut dalam PP No. 34/2002 menyebutkan bahwa bentuk pemanfaatan hutan lindung terbatas pada pemanfaatan kawasan, pemanfaatan jasa lingkungan, dan pemungutan hasil hutan bukan kayu 
(HHBK). Bentuk-bentuk pemanfaatan ini ditujukan untuk meningkatkan pendapatan daerah, peningkatan kesejahteraan dan kesadaran masyarakat sekitar hutan akan fungsi dan kelestarian hutan lindung.

Dalam Tabel 1 dirangkum jenis izin dan bentuk usaha yang boleh dilakukan pada kawasan hutan lindung sebagaimana tercantum dalam UU No 41 Tahun 1999 pasal 26 dan PP No 34 Tahun 2002 pasal 18 s.d pasal 23, sebagai berikut:

Tabel 1 Jenis pemanfaatan dan bentuk usaha yang boleh dilakukan pada kawasan hutan lindung

Table 1. Allowable uses and bussines generatef in protection forests area

\begin{tabular}{|c|c|c|c|c|c|}
\hline No & $\begin{array}{c}\text { Jenis } \\
\text { pemanfaatan } \\
\text { (The kind of } \\
\text { uses) }\end{array}$ & $\begin{array}{c}\text { Bentuk usaha } \\
\text { (Bussiness } \\
\text { generated) }\end{array}$ & $\begin{array}{c}\text { Luas } \\
\text { maksimal } \\
\text { (max.size) }\end{array}$ & $\begin{array}{c}\text { Jangka } \\
\text { waktu } \\
\text { maksimal } \\
\text { (max.time } \\
\text { period }\end{array}$ & $\begin{array}{l}\text { Pembatasan } \\
\text { (Restriction) }\end{array}$ \\
\hline 1 & 2 & 3 & 4 & 5 & 6 \\
\hline 1 & $\begin{array}{l}\text { Pemanfaatan } \\
\text { kawasan }\end{array}$ & $\begin{array}{l}\text { Usaha budidaya } \\
\text { tanaman obat, } \\
\text { tanaman hias, } \\
\text { perlebahan, } \\
\text { jamur, } \\
\text { penangkaran } \\
\text { satwa liar, dan } \\
\text { sarang burung } \\
\text { walet. }\end{array}$ & 50 hektar & 1 tahun & $\begin{array}{l}\text { Tidak boleh } \\
\text { menggunakan } \\
\text { alat berat, } \\
\text { membangun } \\
\text { sarana prasarana } \\
\text { permanen, } \\
\text { dan/atau } \\
\text { mengganggu } \\
\text { fungsi kawasan. }\end{array}$ \\
\hline 2 & $\begin{array}{l}\text { Pemanfaatan } \\
\text { jasa } \\
\text { lingkungan }\end{array}$ & $\begin{array}{l}\text { Usaha wisata } \\
\text { alam, olahraga } \\
\text { tantangan, } \\
\text { pemanfaatan } \\
\text { air, } \\
\text { perdagangan } \\
\text { karbon, dan } \\
\text { penyelamatan } \\
\text { hutan dan } \\
\text { lingkungan. }\end{array}$ & $\begin{array}{l}1000 \\
\text { hektar }\end{array}$ & 10 tahun & $\begin{array}{l}\text { Tidak boleh } \\
\text { menggunakan } \\
\text { sarana dan } \\
\text { prasarana yang } \\
\text { dapat mengubah } \\
\text { bentang alam }\end{array}$ \\
\hline 3 & $\begin{array}{l}\text { Pemungutan } \\
\text { hasil hutan } \\
\text { non kayu }\end{array}$ & $\begin{array}{l}\text { Mengambil } \\
\text { rotan, madu, } \\
\text { buah dan aneka } \\
\text { hasil perburuan } \\
\text { satwa liar yang } \\
\text { tidak dilindungi }\end{array}$ & $\begin{array}{l}\text { Sesuai } \\
\text { dengan } \\
\text { izin }\end{array}$ & 1 tahun & $\begin{array}{l}\text { Tidak boleh } \\
\text { merusak fungsi } \\
\text { utama kawasan } \\
\text { dan melakukan } \\
\text { pemungutan } \\
\text { hasil di luar } \\
\text { undang-undang }\end{array}$ \\
\hline
\end{tabular}




\section{KASUS PENGELOLAAN HUTAN LINDUNG DI KALIMANTAN TIMUR}

Kelembagaan merupakan suatu tatanan dan pola hubungan antara anggota masyarakat yang saling mengikat yang diwadahi dalam suatu organisasi atau jaringan dan ditentukan oleh faktor pembatas berupa norma, kode etik, aturan operasional maupun aturan kolektif untuk bekerja sama dan mencapai tujuan bersama (Djogo, Sunaryo, Suharjito dan Sirait, 2003). Aturan dalam lembaga berfungsi untuk mengarahkan operasional lembaga, mengendalikan perilaku sosial maupun mengatur insentif dalam lembaga.

Kebijakan dan kelembagaan (institusi) sulit dipisahkan. Kebijakan yang baik namun tidak diimplementasikan dalam kelembagaan yang bagus membuat tujuan pembangunan sulit tercapai, demikian pula kelembagaan yang bagus tetapi tidak didukung oleh kebijakan yang berlaku tidak akan mencapai hasil maksimal (Djogo, Sunaryo, Suharjito dan Sirait, 2003).

Salah satu permasalahan dalam pengelolaan hutan lindung adalah perbedaan persepsi antar pemangku kepentingan (stakeholder) mengenai luasan, tata batas, hak pengelolaan, serta pemanfaatan hutan lindung (Ginoga, 2003). Salah satu jalan untuk menyatukan perbedaan persepsi tersebut adalah dengan menerapkan kemitraan (collaborative management) antara pemerintah, masyarakat, dan pemegang peran lain yang terkait.

Berbicara mengenai hutan lindung, Kota Balikpapan dengan Hutan Lindung Sungai Wainnya diakui sebagai pelopor pembentukan lembaga pengelola hutan lindung kolaboratif di Indonesia. Model manajemen kolaboratif dalam pengelolaan hutan lindung telah diterapkan di Hutan Lindung Sungai Wain (HLSW) sejak tahun 2001. Proses pengelolaan hutan lindung dengan sistem manajemen kolaboratif juga telah dimulai di beberapa hutan lindung lainnya di wilayah Kalimantan Timur, antara lain di Hutan Wehea (Kabupaten Kutai Timur), Hutan Lindung Gunung Lumut (Kabupaten Pasir), dan Hutan Lindung Gunung Beratus (Kabupaten Kutai Barat).

Dalam tabel 2 disampaikan beberapa informasi mengenai kelembagaan pengelolaan hutan lindung di Hutan Lindung Sungai Wain (HLSW), Hutan Lindung Gunung Lumut (HLGL), Hutan Lindung Gunung Beratus (HLGB), dan Hutan Wehea (HW) sebagai berikut: 
Tabel 2 Beberapa data yang berkaitan dengan kelembagaan pengelolaan di HLSW HLGL, HW, dan HLGB

Table 2. Some information related to instutional management of HLSW, HLGL, HW, and HLGB

\begin{tabular}{|c|c|c|c|c|c|}
\hline \multirow[t]{2}{*}{ No } & \multirow[t]{2}{*}{ Aspek (Aspects) } & \multicolumn{4}{|c|}{ Hutan Lindung (Protection Forests) } \\
\hline & & HLSW & HLGL & HW & LGBH \\
\hline 1 & 2 & 3 & 4 & 5 & 6 \\
\hline 1 & Luasan & $9.782,80 \mathrm{ha}$ & $35.350 \mathrm{ha}$ & $38.000 \mathrm{ha}$ & $28.261 \mathrm{ha}$ \\
\hline 2 & Status hutan & $\begin{array}{l}\text { Hutan } \\
\text { Lindung }\end{array}$ & $\begin{array}{l}\text { Hutan } \\
\text { Lindung }\end{array}$ & $\begin{array}{l}\text { Hutan } \\
\text { Produksi }\end{array}$ & $\begin{array}{l}\text { Hutan } \\
\text { Lindung }\end{array}$ \\
\hline 3 & $\begin{array}{l}\text { Dasar hukum } \\
\text { terakhir } \\
\text { mengenai status } \\
\text { sebagai hutan } \\
\text { lindung }\end{array}$ & $\begin{array}{l}\text { SK Menteri } \\
\text { Kehutanan } \\
\text { No. } 416 / \text { Kpts - } \\
11 / 1995 .\end{array}$ & $\begin{array}{l}\text { SK Menteri } \\
\text { Kehutanan } \\
\text { No.24/Kpts/ } \\
\text { Um/1983 }\end{array}$ & $\begin{array}{l}\text { Belum ada } \\
\text { (telah } \\
\text { diusulkan } \\
\text { menjadi Hutan } \\
\text { Lindung) }\end{array}$ & $\begin{array}{l}\text { SK Menteri } \\
\text { Kehutanan No } \\
321 / \text { Kpts- } \\
\text { II/1992 }\end{array}$ \\
\hline 4 & $\begin{array}{l}\text { Nama DAS yang } \\
\text { dilindungi }\end{array}$ & $\begin{array}{l}\text { DAS Wain, } \\
\text { DAS Bugis }\end{array}$ & $\begin{array}{l}\text { DAS } \\
\text { Kandilo, } \\
\text { DAS Telake } \\
\end{array}$ & DAS Wahau & $\begin{array}{l}\text { DAS } \\
\text { Mahakam }\end{array}$ \\
\hline 5 & $\begin{array}{l}\text { Lembaga } \\
\text { Pengelola }\end{array}$ & $\begin{array}{l}\text { Badan } \\
\text { Pengelola } \\
\text { HLSW } \\
\text { (kolaboratif) }\end{array}$ & $\begin{array}{l}\text { Pokja } \\
\text { Pengelolaan } \\
\text { HLGL }\end{array}$ & $\begin{array}{l}\text { Badan } \\
\text { Pengelola HL } \\
\text { Wehea } \\
\text { (kolaboratif) }\end{array}$ & $\begin{array}{l}\text { Pokja } \\
\text { Penyiapan } \\
\text { Lembaga } \\
\text { Pengelola }\end{array}$ \\
\hline 6 & $\begin{array}{l}\text { Dasar hukum } \\
\text { lembaga } \\
\text { pengelola }\end{array}$ & $\begin{array}{l}\text { SK Walikota } \\
\text { Balikpapan } \\
\text { No } 6 / 2001 \\
\text { dan No } 14 \\
\text { Tahun } 2004\end{array}$ & $\begin{array}{l}\text { SK Bupati } \\
\text { Pasir No } 340 \\
\text { Tahun } 2005\end{array}$ & $\begin{array}{l}\text { SK Bupati } \\
\text { Kutai Timur } \\
\text { No } \\
44 / 02.188 .45 / \\
\mathrm{HK} / \mathrm{II} / 2005\end{array}$ & $\begin{array}{l}\text { Belum } \\
\text { terbentuk } \\
\text { lembaga } \\
\text { pengelola }\end{array}$ \\
\hline 7 & $\begin{array}{l}\text { Inisiator proses } \\
\text { pembentukan } \\
\text { lembaga } \\
\text { pengelola }\end{array}$ & $\begin{array}{l}\text { Peneliti, LSM } \\
\text { lokal (YBML } \\
\text { \& Lories) dan } \\
\text { LSM } \\
\text { internasional } \\
\text { (Natural } \\
\text { Resource } \\
\text { Management) }\end{array}$ & $\begin{array}{l}\text { LSM } \\
\text { internasional } \\
\text { (Tropenbos } \\
\text { International } \\
\text { - Indonesia), } \\
\text { Pemerintah } \\
\text { Kabupaten } \\
\text { (Pemkab) } \\
\text { Pasir }\end{array}$ & $\begin{array}{l}\text { LSM } \\
\text { internasional } \\
\text { (The Nature } \\
\text { Conservancy), } \\
\text { perguruan } \\
\text { tinggi (Univ. } \\
\text { Mulawarman), } \\
\text { Pemkab Kutai } \\
\text { Timur }\end{array}$ & $\begin{array}{l}\text { LSM nasional } \\
\text { (Yayasan } \\
\text { Borneo } \\
\text { Orangutan } \\
\text { Survival), } \\
\text { Pemkab Kutai } \\
\text { Barat }\end{array}$ \\
\hline 8 & $\begin{array}{l}\text { Pihak-pihak } \\
\text { yang terlibat } \\
\text { dalam Badan } \\
\text { Pengel ola }\end{array}$ & $\begin{array}{l}\text { Pemerintah } \\
\text { Kota (Pemkot) } \\
\text { Balikpapan, } \\
\text { LSM, } \\
\text { Perguruan } \\
\text { Tinggi, Swasta, } \\
\text { masyarakat }\end{array}$ & $\begin{array}{l}\text { LSM, } \\
\text { Perguruan } \\
\text { Tinggi, } \\
\text { Pemkab } \\
\text { Pasir, } \\
\text { masyarakat, } \\
\text { swasta }\end{array}$ & $\begin{array}{l}\text { BKSDA, } \\
\text { Pemkab Kutai } \\
\text { Timur, } \\
\text { Perguruan } \\
\text { tinggi, LSM, } \\
\text { masyarakat } \\
\text { adat }\end{array}$ & $\begin{array}{l}\text { Belum } \\
\text { terbentuk }\end{array}$ \\
\hline 9 & $\begin{array}{l}\text { Sumber dana } \\
\text { pengelolaan }\end{array}$ & $\begin{array}{l}\text { APBD, } \\
\text { donatur tak } \\
\text { mengikat }\end{array}$ & $\begin{array}{l}\text { Pemkab } \\
\text { Pasir (selama } \\
\text { belum ada } \\
\text { lembaga } \\
\text { pengelola) }\end{array}$ & $\begin{array}{l}\text { APBD } \\
\text { kabupaten dan } \\
\text { subsidi APBD } \\
\text { propinsi }\end{array}$ & $\begin{array}{l}\text { Pemkab Kutai } \\
\text { Barat (selama } \\
\text { belum ada } \\
\text { lembaga } \\
\text { pengelola) }\end{array}$ \\
\hline
\end{tabular}

Keterangan : Diolah dari berbagai sumber 


\section{A. Fungsi dan Status Beberapa Kawasan Hutan Lindung di Kalimantan Timur}

Bila dicermati kriteria hutan lindung dalam PP 44/2004 pasal 24 ayat 3 (b) masih bersifat umum, sehingga sebagian besar kawasan hutan apapun fungsinya akan dapat memenuhi salah satu kriteria tersebut. Konsekuensi dari luasnya kriteria penetapan hutan lindung tersebut antara lain adalah luasnya kemungkinan perubahan tataguna hutan yang semula merupakan hutan produksi yang kewenangan pengelolaannya di tangan pemerintah pusat (pada hutan produksi pemerintah pusat berhak menetapkan kepada siapa hak konsesi diserahkan) menjadi hutan lindung agar pengelolaannya dapat diserahkan pada daerah tingkat II. Hal ini terjadi di Hutan Wehea, Kabupaten Kutai Timur. Statusnya semula adalah hutan produksi yang hak konsesinya dipegang PT Gruti III. Kegiatan perusahaan tersebut sudah dihentikan sejak tahun 1993. Tahun 2000 nama PT Gruti III diganti menjadi PT Dwiloka Hutani Raya (PT LDR), perusahaan patungan antara PT Gruti III dan PT Inhutani II. Tanggal 15 Desember 2000 Badan Planologi Kehutanan dan Perkebunan mengeluarkan surat kepada Dirjen Pengelolaan Hutan Produksi No 240/RHS/VII-INV/2000 mengenai peta areal kerja a.n. PT LDR seluas 38.00 ha, dengan fungsi hutan sebagai hutan produksi terbatas. Namun hingga tahun 2006 Departemen Kehutanan belum mengeluarkan SK pengelolaan dan RKPH untuk PT LDR di kawasan eks PT Gruti III.

Hasil survei potensi keanekaragaman hayati yang dilakukan The Nature Conservancy serta tim kolaboratif yang dibentuk Pemerintah Propinsi Kalimantan Timur menyatakan bahwa kondisi hutan masih bagus dan layak sebagai habitatorangutan. Tahun 2005 Pemerintah Kabupaten Kutai Timur dengan persetujuan Gubernur Propinsi Kalimantan Timur mengajukan usulan perubahan fungsi kawasan tersebut dari hutan produksi menjadi kawasan hutan lindung (Pemerintah Kabupaten Kutai Timur, 2005). Namun hingga bulan Maret 2006 pemerintah pusat (dalam hal ini Menteri Kehutanan) belum menetapkan perubahan status kawasan tersebut. Perubahan fungsi kawasan dari kawasan hutan produksi menjadi kawasan lindung didukung oleh Lembaga Adat setempat dengan SK Ketua Lembaga Edat Besar Dayak Kutai Timur No 095/LAB-D/KT-SK/XI/2004 yang menetapkan kawasan tersebut sebagai Kawasan Hutan Lindung Adat dengan nama "Letaah Laas Wehea Long Skung Meguen".

Bila ditinjau dari UU No 41/99, fungsi utama hutan lindung adalah fungsi hidrologis sebagai penyangga tata air, mencegah banjir, mengendalikan erosi, dan memelihara kesuburan tanah. Namun bila dilihat dari beberapa contoh inisiasi proses pembentukan lembaga pengelola hutan lindung di Kalimantan Timur, isu utama yang mendorong inisiator adalah kepentingan pelestarian keanekaragaman hayati terutama fauna langka dan habitatnya, misal orangutan di HLGB dan HW, dan beruang madu di HLSW. Meski demikian motivasi pengelolaan hutan lindung untuk pelestarian habitat satwa tersebut berarti juga melestarikan fungsi utama hutan lindung sebagai penyangga tata air, juga masih terliput dalam lingkup fungsi yang disebutkan dalam PP 34/2002. Namun untuk kepentingan strategi pengelolaan hutan lindung selanjutnya, fungsi hidrologi hutan lindung harus diutamakan dengan tidak melupakan fungsi konservasinya. 


\section{J umal AnalisisKedijakanKedutanan}

Vo. 4No. 1, Mare 2007: 1- 19

\section{B. Lembaga Pengelola Hutan Lindung}

Dari keempat hutan yang menjadi contoh kasus tersebut, lembaga pengelola hutan lindung baru terbentuk di HLSW dan HW. Berdasar PP No 62 Tahun 1998, kewenangan pengelolaan hutan lindung berada pada pemerintah daerah tingkat II. Menurut PP No 34 Tahun 2002, hak pemanfaatan hutan lindung dapat diberikan kepada pihak lain dengan luasan dan jangka waktu yang terbatas. Oleh karena itu agar pengelolaan hutan lindung dapat melingkupi satu kawasan secara utuh dan berkelanjutan, lembaga pengelola hutan lindung dibentuk berdasar SK Kepala Daerah tingkat II. Contohnya Badan Pengelola HLSW (BPHLSW) yang dibentuk berdasar SK Walikota Balikpapan No 6 Tahun 2001 dan diatur lebih lanjut dengan SK Walikota Balikpapan No 14 Tahun 2004 yang menyatakan fungsi BPHLSW adalah untuk menetapkan kebijakan internal dan teknik operasional pengelolaan HLSW, sebagai wadah koordinasi dan konsultasi kebijakan antar instansi terkait, dan penggalangan dana dalam rangka pengelolaan HLSW.

Di Hutan Wehea, meski secara hukum belum berstatus hutan lindung, Pemerintah Kabupaten Kutai Timur telah membentuk lembaga pengelola yang disebut Badan Pengelola Hutan Lindung Wehea (BPHLW) berdasar SK Bupati Kutai Timur No 44/02.188.45/HK/II/2005. Dalam SK tersebut disebutkan bahwa fungsi lembaga pengelola adalah sebagai perencana, pengelola, pusat informasi dan program, serta pusat penggalangan dana bagi kawasan Hutan Lindung Wehea.

Di satu sisi pembentukan BPHLW ini menunjukkan adanya penyimpangan dalam hierarki peraturan perundangan. Kewenangan pengelolaan masih berada pada pemerintah pusat, fungsi hutan masih sebagai hutan produksi namun pemerintah daerah telah menerbitkan peraturan pengelolaan kawasan hutan Wahea. Di sisi lain berdasar hasil wawancara dengan salah satu insiator pembentukan BPHLW, lembaga tersebut dibentuk karena melihat urgensinya bagi pelestarian kawasan tersebut, terutama untuk mengamankan kawasan dari ancaman penebangan liar dan konversi hutan menjadi perkebunan. Proses alih fungsi kawasan tersebut hingga dilegalkan sebagai kawasan lindung atau kawasan konservasi dengan SK Menteri Kehutanan akan memakan waktu karena prosedur penetapan peraturan yang cukup panjang. Dikhawatirkan kawasan tersebut akan rusak apabila tidak segera dikelola dengan terarah oleh suatu lembaga kolaboratif. Dukungan Bupati Kutai Timur terhadap perubahan fungsi hutan lindung yang ditunjukkan dengan munculnya SK pembentukan Badan Pengelola tersebut kemudian diikuti oleh instansi-instansi pemerintah kabupaten seperti Dinas Kehutanan dan Dinas Perkebunan, yang pada akhirnya menggagalkan beberapa pengajuan Ijin Usaha Pemanfaatan Kayu dan pengajuan hak konversi kawasan Hutan Wehea menjadi perkebunan.

Di HLGL belum ada lembaga pengelola seperti di HLSW dan HW, namun Bupati Pasir telah membentuk Kelompok Kerja Pengelolaan Hutan Lindung Gunung Lumut (Pokja HLGL) dengan tugas mengkoordinasikan kegiatan pemeliharaan, pelestarian fungsi HLGL sebagai kawasan penyangga bagi kawasan di sekitarnya (SK Bupati Pasir No 340 Tahun 2005). Sedang di HLGB, hingga bulan Agustus 2006 proses pembentukan lembaga pengelola kolaboratif multipihak baru sampai pada tahap 
pembentukan Kelompok Kerja Penyiapan Badan Pengelola Hutan Lindung Gunung Beratus (Pokja HLGB).

Karena ditetapkan dengan keputusan Kepala Daerah tingkat II, BPHLSW, BPHLW, dan Pokja Pengelolaan HLGL menjadi lembaga pemerintah non struktural. Jadi meskipun beranggotakan berbagai pihak (multistakeholder), BPHLSW dan BPHLW bertanggung jawab kepada Pemerintah Daerah masing-masing, serta mendapatkan dana pengelolaan dari APBD melalui instansi pemerintah daerah tingkat II, yaitu Bapedalda di Balikpapan dan Dinas Lingkungan Hidup di Kutai Timur. Selain itu masing-masing lembaga pengelola juga berhak mendapat bantuan dana pengelolaan yang tidak mengikat.

\section{Kegiatan yang dilakukan Lembaga Pengelola dalam Pengelolaan Hutan Lindung}

Berdasarkan PP 62/1998 pasal 6 ayat 5, wewenang Daerah Tingkat II dalam pengelolaan hutan lindung meliputi kegiatan pemancangan batas, pemeliharaan batas, mempertahankan luas dan fungsi hutan lindung, pengendalian kebakaran, reboisasi dalam rangka rehabilitasi lahan kritis pada kawasan hutan lindung, dan pemanfaatan jasa lingkungan.

\section{Kegiatan dalam rangka penyelenggaraan tata batas hutan lindung}

Di HLSW yang kelembagaan pengelolanya telah berjalan sejak tahun 2001, penataan batas telah diselenggarakan secara de jure maupun de facto di lapangan. Pemerintah Kota Balikpapan bahkan telah mengeluarkan SK Walikota No 13 Tahun 2004 tentang Penataan dan Pemanfaatan Kawasan Hutan Lindung Sungai Wain, yang membagi kawasan HLSW menjadi blok perlindungan, blok pemanfaatan, dan blok kegiatan terbatas. Selain pembagian blok diatas, disekitar kawasan HLSW juga ditetapkan zona penyangga atau yang disebut juga dengan buffer zone. Pembagian kawasan dalam blok ini masih memerlukan proses sosialiasi kepada masyarakat baik mengenai batas-batas bloknya maupun pengaturan kegiatan yang boleh dan tak boleh dilakukan pada masing-masing blok.

Di HLGL, penataan batas yang dilakukan baru sampai pada tahap dikeluarkan SK penunjukan sebagai hutan lindung (SK Menteri Kehutanan No.24/kpts/Um/1983), namun hingga bulan Februari 2006 belum ada kegiatan penataan batas dan pengukuhan kawasan. Sedangkan di HLGB meskipun sudah dilakukan penunjukan dan penataan batas, tata batas hutan lindung belum disosialisasikan kepada masyarakat (Hasil Semiloka HLGB, 2005). Di HW karena status belum jelas, belum dilakukan penataan batas. Kawasan yang diusulkan sebagai hutan lindung adalah seluruh kawasan eks HPH PT Gruti III seluas 38.000 hektar.

\section{Kegiatan dalam rangka perlindungan hutan}

Beberapa gangguan bagi kelestarian hutan lindung adalah adanya kegiatan penebangan liar, perburuan satwa liar, serta kebakaran hutan. Kegiatan perlindungan hutan menjadi salah satu tanggung jawab lembaga pengelola hutan lindung yang mendapat mandat pengelolaan dari Pemerintah Daerah Tingkat II. 


\section{J umal AnalisisKedijakanKedutanan}

Vo. 4No. 1, Mare 2007: 1- 19

Sejak terbentuknya BPHLSW pada tahun 2001, Unit Pelaksana BPHLSW telah berhasil menekan laju penebangan liar dan perburuan satwa yang dilindungi hingga menjadi 0\% pada tahun 2005. Kegiatan perlindungan dilakukan oleh Tim Pengamanan gabungan dari unsur TNI, Polri, dan masyarakat. Unsur masyarakat makin besar perannya sejak tahun 2005 dengan pembentukan Tim Pengamanan (PAM) Swakarsa yang beranggotakan warga masyarakat. Tugas Tim Pengaman ini termasuk melakukan kegiatan pencegahan dan pemadaman kebakaran hutan.

Di HW yang merupakan hutan adat, BPHLW membentuk Tim Pengamanan yang diberi nama lokal "Petkuq Mehuey Keldung Laas Wehea" yang berarti penjaga hutan lindung Wehea. Tim Pengamanan ini beranggotakan masyarakat adat, dan bertugas menjaga dan mengamankan kawasan hutan dari segala bentuk kegiatan yang dapat menyebabkan kerusakan hutan, termasuk penebangan liar, perburuan, dan patroli kebakaran.

Di HLGL dan HLGB yang belum ada badan pengelolanya, kegiatan pengamanan masih dilakukan oleh pemerintah kabupaten. Hingga Februari 2006, kegiatan penebangan dan perburuan liar masih mengancam kelestarian kedua kawasan hutan lindung tersebut.

\section{Reboisasi dalam rangka rehabilitasi lahan kritis di kawasan hutan lindung}

Di HLSW, HW, HLGL, dan HLGB, kegiatan reboisasi dalam rangka rehabilitasi lahan kritis dilaksanakan oleh Pemerintah Daerah Tingkat II melalui Dinas Kehutanan atau Bapedalda setempat dalam bentuk proyek dari sumber dana DAK-DR yang kemudian digantikan oleh sumber dana Gerakan Nasional Rehabilitasi Hutan dan Lahan (GNRHL). Dalam kegiatan ini Pemerintah Daerah umumnya menyediakan bibit, pupuk, dan dana penanaman sampai pemeliharaan, dengan melibatkan masyarakat setempat sebagai pelaksana teknis di lapangan.

\section{Pemanfaatan Hutan Lindung}

Dalam SK Walikota Balikpapan No 13 Tahun 2004 mengenai kebijakan pemanfaatan kawasan di HLSW terdapat beberapa tambahan tentang jenis usaha dan pemanfaatan yang boleh dilakukan pada kawasan hutan hutan lindung, yaitu:

a. Bentuk usaha pemanfaatan kawasan di HLSW mendapat tambahan yaitu kegiatan agroforestry atau wanatani yang dilakukan dengan pertimbangan luasnya kawasan yang telah dirambah dan dijadikan kebun oleh masyarakat. Kawasan yang telah dirambah tersebut kemudian dijadikan blok pemanfaatan, dimana setiap kepala keluarga berhak mendapat izin pemanfaatan lahan maksimal 2 (dua) hektar dalam jangka waktu maksimal 5 (lima) tahun. Izin usaha ini diberikan oleh Ketua Bapedalda dengan rekomendasi dari BPHLSW, dan tidak dapat dipindahtangankan. Ketentuan tentang perizinan pemanfaatan kawasan diatur dalam SK Walikota Balikpapan No 15 Tahun 2004. Sedang kegiatan pemanfaatan kawasan selain agroforestry belum dilakukan oleh masyarakat di kawasan tersebut.

b. Bentuk kegiatan pemanfaatan jasa lingkungan yang boleh dilakukan di HLSW adalah kegiatan penelitian, kunjungan formal, kunjungan pendidikan dan pelatihan, olah raga tantangan, dan kunjungan ekowisata. Kegiatan tersebut dapat dilakukan di blok perlindungan, blok kegiatan terbatas, maupun di blok pemanfaatan dengan syarat harus disesuaikan dengan daya dukung lingkungan/blok dan tidak mengubah bentang 
alam. Izin pemanfaatan jasa lingkungan diberikan oleh Walikota dengan rekomendasi dari instansi teknis terkait dan BP HLSW.

c. Bentuk kegiatan pemungutan hasil hutan non kayu yang diperbolehkan adalah pemungutan rotan, buah, madu, tanaman obat, dan hasil hutan non kayu lainnya yang tidak mengganggu fungsi lingkungan yang semuanya dapat dilakukan di blok pemanfaatan. Di blok kegiatan terbatas hanya diperbolehkan pengambilan rotan untuk keperluan perajin atap daun nipah dengan jangka pemberian izin maksimal 1 tahun dan dapat diperpanjang. Izin diberikan oleh BP HLSW melalui Unit Pelaksana BPHLSW.

Di HLGL pemerintah daerah belum membuat kebijakan pemanfaatan khusus untuk kawasan hutan lindung, jadi masih mengacu pada tabel 2 di atas. Demikian juga di HLGB. HLGB menjadi tempat pelepasliaran orangutan dari Wanariset Samboja dengan izin dari Dirjen PHKA.

Di HW, lembaga adat membuat Keputusan Edat Desa Nehas Liah Bing Nomor 01 Tahun 2005 tentang Perlindungan dan Pemanfaatan Terbatas "Keldung Laas Wehea Long Skung Metgueen”. Dalam tabel 4 disebutkan kegiatan yang boleh dan tidak boleh dilakukan di kawasan Keldung Laas Wehea Long Skung Metgueen menurut Hukum Edat Wehea sebagai berikut:

Tabel 3 Kegiatan yang boleh dan tidak boleh dilakukan di Keldung Laas Wehea Table 3. Permitted and forbidden activities in Keldung Laas Wehea

\begin{tabular}{|c|c|c|}
\hline No & $\begin{array}{l}\text { Kegiatan yang boleh dilakukan di } \\
\text { Keldung Laas Wehea ( Permitted } \\
\text { Activities in Keldung Laas Webea ) }\end{array}$ & $\begin{array}{l}\text { Kegiatan yang tidak boleh } \\
\text { dilakukan di Keldung Laas } \\
\text { Wehea (Forbidden activities } \\
\text { in Keldung Laas Webea) }\end{array}$ \\
\hline 1 & 2 & 3 \\
\hline 1 & $\begin{array}{l}\text { Memaanfaatkan hasil hutan bukan } \\
\text { kayu seperti rotan, damar, buah - } \\
\text { buahan dan gaharu setelah mendapat } \\
\text { ijin tertulis dari BPHLW, Ketua } \\
\text { Lembaga Edat, Pemerintahan Desa } \\
\text { dan Petkuq Mehuey. }\end{array}$ & $\begin{array}{l}\text { Membuka lahan untuk } \\
\text { kegiatan ladang, kebun dan } \\
\text { atau peruntukan lainnya di } \\
\text { dalam kawasan Keldung Laas } \\
\text { Wehea. }\end{array}$ \\
\hline 2. & $\begin{array}{l}\text { Hasil hutan kayu dapat } \\
\text { dimanfaatkan hanya untuk keperluan } \\
\text { pembangunan fasilitas umum } \\
\text { (eweang/balai adat dan } \\
\text { serapoh/balai desa) dengan jumlah } \\
\text { terbatas setelah mendapat } \\
\text { persetujuan dalam bentuk ijin } \\
\text { tertulis dari BPHLW, Ketua } \\
\text { Lembaga Edat, Pemerintahan Desa } \\
\text { dan Petkuq Mehuey. }\end{array}$ & $\begin{array}{l}\text { Membuat api di dalam atau di } \\
\text { luar kawasan kecuali untuk } \\
\text { memasak dan harus dipastikan } \\
\text { sudah padam sebelum } \\
\text { meninggalkan tempat } \\
\text { bermalam. }\end{array}$ \\
\hline
\end{tabular}




\begin{tabular}{|l|l|l|}
\hline 3. & $\begin{array}{l}\text { Berburu binatang babi (Jiem) setelah } \\
\text { mendapat ijin tertulis dari BPHLW, } \\
\text { Ketua Lembaga Edat, Pemerintahan } \\
\text { desa dan Petkuq Mehuey. } \\
\text { Ijin berburu diberikan dalam jumlah } \\
\text { terbatas dan waktu-waktu tertentu } \\
\text { untuk memberi kesempatan } \\
\text { berkembang biak. }\end{array}$ & $\begin{array}{l}\text { Melakukan kegiatan } \\
\text { penebangan pohon untuk } \\
\text { kepentingan pribadi atau } \\
\text { diperjualbelikan. }\end{array}$ \\
\hline 4. & $\begin{array}{l}\text { Berburu satwa dan mengambil } \\
\text { pohon/tumbuhan yang } \\
\text { dilindungi undang-undang dan } \\
\text { atau edat. }\end{array}$ \\
\hline
\end{tabular}

Apabila terjadi pelanggaran terhadap ketentuan yang tercantum dalam tabel 3 di atas, maka akan dikenakan Sanksi Edat Wehea berupa penyitaan hasil-hasil yang diambil dari dalam kawasan dan dikenakan denda edat berupa babi dan menanggung seluruh biaya upacara adat untuk pemulihan atas kesalahan tersebut.

Salah satu bentuk pemanfaatan jasa lingkungan pada hutan lindung yang sangat potensial adalah pemanfaatan air. Keempat hutan lindung dalam penelitian ini memiliki fungsi hidrologis sebagai pelindung daerah tangkapan air (catchment area). Insentif pemanfaatan air dapat menjadi sumber dana pengelolaan yang potensial, namun dari keempat hutan lindung tersebut hanya HLSW yang mendapat insentif air permukaan dari Pertamina UP V yang dibayarkan kepada Pemerintah Propinsi Kalimantan Timur. Belum ada insentif pemakaian air dari Pertamina sebagai konsumen utama air dari Waduk Wain yang diberikan kepada Pemerintah Kota Balikpapan. Baik UU No 7 Tahun 2004 tentang Sumberdaya Air maupun UU No 33 Tahun 2004 tentang Perimbangan Keuangan juga tidak menyebutkan ketentuan mengenai insentif pemakaian air kepada pengelola hutan lindung ataupun pembagian pendapatan dana insentif air antara pemerintah propinsi dan pemerintah daerah tingkat II.

Dalam PP 34/2002 Pasal 38 ayat 4 disebutkan pada kawasan hutan dilarang melakukan penambangan dengan pola pertambangan terbuka. Namun dalam UU No 19 tahun 2004 dinyatakan bahwa secara hukum perizinan atau perjanjian di bidang pertambangan di kawasan hutan sebelum berlakunya UU No. 41/1999 dinyatakan tetap berlaku sampai berakhirnya izin atau perjanjian tersebut. Sehingga ijin pertambangan terbuka di hutan lindung yang dikeluarkan setelah berlakunya UU 41/1999 harus dinyatakan batal demi hukum (Darusman \& Nurrochmat, 2005). Ada 13 perusahaan yang masih diizinkan melakukan penambangan di hutan lindung berdasarkan Perpu No 1 Tahun 2004. Namun tidak satupun yang berada di HLSW, HW, HLGL, maupun HLGB. Namun demikian bukan berarti keempat hutan lindung tersebut bebas dari ancaman pembukaan tambang, sebab beberapa perusahaan tambang batubara telah beroperasi di kawasan sekitar hutan-hutan lindung tersebut sehingga tetap diperlukan pengawasan agar perusahaan tambang batubara tersebut tidak melakukan kegiatannya di daerah batas hutan lindung. 


\section{KESIMPULAN DAN SARAN}

\section{A. Kesimpulan}

1. Salah satu jalan menyatukan perbedaan persepsi mengenai pengelolaan hutan lindung adalah dengan menerapkan manajemen kemitraan multipihak. Badan pengelola hutan lindung multipihak telah dibentuk di Hutan Lindung Sungai Wain (HLSW) Balikpapan dan Hutan Wehea (HW) Kabupaten Kutai Timur. Di Hutan Lindung Gunung Lumut (HLGL) peran lembaga pengelola yang multipihak masih dijalankan oleh Kelompok Kerja Pengelolaan HLGL. Sedang di Hutan Lindung Gunung Beratus, hingga bulan Agustus 2006, proses pembentukan lembaga pengelola kolaboratif multipihak baru sampai pada tahap pembentukan Kelompok Kerja Penyiapan Badan Pengelola HLGB.

2. Bila ditinjau dari UU No 41/1999, fungsi utama hutan lindung adalah fungsi hidrologis sebagai penyangga tata air, mencegah banjir, mengendalikan erosi, dan memelihara kesuburan tanah. Namun fungsi konservasi juga menjadi strategi efektif pada beberapa contoh kasus inisiasi proses pembentukan lembaga pengelola hutan lindung di Kalimantan Timur, dimana isu utama yang mendorong inisiator adalah kepentingan pelestarian keanekaragaman hayati terutama fauna langka dan habitatnya, yaitu orangutan di HLGB dan HW, serta beruang madu di HLSW. Inisiasi pembentukan lembaga pengelola hutan lindung ini sejalan dengan kebutuhan dan didukung oleh pemerintah daerah tingkat II setempat.

3. Ketidaksesuaian antara kebijakan pemerintah pusat dengan pemerintah daerah terjadi di Hutan Wehea. Meski status fungsi kawasan tersebut adalah hutan produksi, pemerintah Kabupaten Kutai Timur telah membentuk lembaga pengelola dengan nama Badan Pengelola Hutan Lindung Wehea dengan alasan kekhawatiran akan terjadi kerusakan hutan dan ekosistem di dalamnya bila tidak segera dikelola oleh suatu lembaga pengelola kolaboratif.

4. Pada kawasan hutan yang telah mempunyai Badan Pengelola seperti HLSW dan HW, pelaksanaan kegiatan perlindungan hutan berjalan lebih efektif dengan dibentuknya tim pengamanan yang melibatkan masyarakat. Demikian juga kegiatan pemanfaatan hutan lebih terarah dengan diterbitkannya kebijakan pemerintah dan lembaga adat mengenai pemanfaatan kawasan hutan dan perizinannya.

5. Di HLSW, HW, HLGL, dan HLGB potensi pemanfaatan jasa lingkungan berupa air belum dimanfaatkan secara optimal untuk kepentingan dana pengelolaan hutan lindung, misalnya dengan memungut insentif pemakaian air dari konsumen. Peraturan Perundangan yang berlaku juga belum mencantumkan kewajiban konsumen membayar insentif pemakaian air bagi kepentingan pengelolaan hutan lindung.

\section{B. Saran}

1. Peningkatan peran Pemerintah Daerah Tingkat II sebagai pemegang kewenangan pengelolaan hutan lindung sangat diperlukan dalam kelanjutan proses pembentukan lembaga pengelola di HLGL dan HLGB, juga dalam mendorong perubahan fungsi Hutan Wehea menjadi hutan lindung. 


\section{J umal AnalisisKedijakanKedutanan}

Vo. 4No. 1, Mare 2007: 1- 19

2. Untuk mengoptimalkan fungsi hutan-hutan lindung tersebut, perlu dilakukan penelitian lebih lanjut mengenai nilai ekologi dan ekonomi pemanfaatan jasa lingkungan air. Selain sebagai dasar perencanaan pengelolaan dan berpotensi pula sebagai sumber dana pengelolaan hutan lindung.

3. Perlu ditetapkan kebijakan dalam peraturan perundangan pusat maupun daerah mengenai kewajiban konsumen membayar insentif pemakaian air bagi kepentingan pengelolaan hutan lindung.

\section{DAFTAR PUSTAKA}

Badan Planologi, Departemen Kehutanan. 2002. Statistik Kehutanan Indonesia. http://www.dephut.go.id.

Darusman dan Nurrochmat. 2005. Kebijakan dan Kerangka Hukum Kehutanan Menuju Tata Kelola Hutan yang Baik di Kabupaten Pasir, Malinau, dan Kapuas Hulu. Makalah dalam Workshop "Knowledge and Sustainable Forest Management", Expose of TBI Indonesia-MTKP's Programme.

Djogo, T., Sunaryo, Suhardjito, D. Dan Sirait, M. 2003. Kelembagaan dan Kebijakan dalam Pengembangan Agroforestri, Bahan Ajaran Agroforestri no 8. ICRAF, Bogor.

Ginoga, K. 2003. Usulan Kegiatan Penelitian Kajian Pengelolaan Hutan Lindung. Badan Litbang Kehutanan. Tidak dipublikasikan.

Ginoga, K., Djainuddin, D., \& Lugina, M. 2004. Laporan Hasil Penelitian Kajian Kebijakan Pengelolaan Hutan Lindung. Pusat Penelitian dan Pertimbangan Sosial Ekonomi dan Kebijakan Kehutanan. Bogor. Tidak dipublikasikan.

Keputusan Badan Pengelola Hutan Lindung Wehea Kabupaten Kutai Timur tentang Pembentukan Team Pengamanan Hutan Lindung Wehea.

Keputusan Bupati Kutai Timur No 44/02.188.45/HK/II/2005 tentang Pembentukan Badan Pengelola Hutan Lindung Wehea "Long Skung Metgueen."

Keputusan Bupati Pasir No 340 Tahun 2005 tentang Pembentukan Kelompok Kerja Pengelolaan Hutan Lindung Gunung Lumut.

Keputusan Edat Desa Nehes Liah Bing Kecamatan Muara Wahau Kabupaten Kutai Timur No 01 Tahun 2005 tentang Perlindungan dan Pemanfaatan Terbatas "Keldung Laas Wehea Long Skung Metgueen".

Keputusan Presiden No 32 Tahun 2004 tentang Pengelolaan Kawasan Lindung. 
Keputusan Walikota Balikpapan No 6 Tahun 2001 tentang Pembentukan Badan Pengelola Hutan Lindung Sungai Wain.

Keputusan Walikota Balikpapan No 13 Tahun 2004 tentang Penataan dan Pemanfaatan Kawasan Hutan Lindung Sungai Wain.

Keputusan Walikota Balikpapan No 14 Tahun 2004 tentang Pembentukan Badan Pengelola Hutan Lindung Sungai Wain.

Keputusan Walikota Balikpapan No 15 Tahun 2004 tentang Pedoman dan Tata Cara Pemberian Izin Kegiatan Pemanfaatan Kawasan Hutan Lindung Sungai Wain.

Khakim, A. 2005. Pengantar Hukum Kehutanan Indonesia dalam Era Otonomi Daerah. PT Citra Aditya Bakti. Bandung.

Pemerintah Kabupaten Kutai Barat, Ditjen PHKA, dan Yayasan BOS. 2005. Laporan Semiloka Hutan Lindung Gunung Beratus di Kabupaten Kutai Barat. Dari Agenda ke Aksi Bersama Pengelolaan. Tidak dipublikasikan.

Pemerintah Kabupaten Kutai Timur. 2005. Usulan Perubahan Fungsi Kawasan Hutan Eks HPH Gruti III sebagai Kawasan Hutan Lindung Wehea'Long Skung Metgueen" di Kabupaten Kutai Timur. Tidak dipublikasikan.

Peraturan Pemerintah No 62 Tahun 1998 tentang Penyerahan Sebagian Urusan Pemerintahan di Bidang Kehutanan kepada Daerah.

Peraturan Pemerintah No 25 Tahun 2000 tentang Kewenangan Propinsi dalam Otonomi Daerah.

Peraturan Pemerintah No 34 Tahun 2002 tentang Tata Guna dan Penyusunan Rencana Pengelolaan Hutan Pemanfaatan Hutan dan Penggunaan Kawasan Hutan.

Peraturan Pemerintah No 44 Tahun 2004 tentang Perencanaan Hutan.

Peraturan Pemerintah No 45 Tahun 2004 tentang Perlindungan Hutan.

Sarjono, M.A., Soedirman,S., Kuncoro,I., Rujehan, dan Kamaruddin. 2005. Parapihak Kehutanan di Kalimantan. Ringkasan Eksekutif disampaikan dalam Workshop Pengetahuan dan Pengelolaan Hutan Berkelanjutan, Ekspose TBI Indonesia/Program MTKP. Tropenbos International Indonesia bekerjasama dengan Kelompok Kajian Pembangunan Kehutanan. Balikpapan.

Undang-undang Republik Indonesia No 41 Tahun 1999 tentang Kehutanan. 
Undang-undang No 10 Tahun 2004 tentang Pembentukan Peraturan Perundangundangan.

Undang-undang No 32 Tahun 2004 tentang Pemerintah Daerah.

Undang-undang No 33 Tahun 2004 tentang Perimbangan Keuangan antara Pemerintah Pusat dan Pemerintah Daerah. 


\section{Lampiran}

Tabel 4 Beberapa peraturan perundangan yang berkaitan langsung dengan pengelolaan hutan lindung

Table 4. Some regulations directly related to management of protection forest

\begin{tabular}{|c|c|c|}
\hline No & $\begin{array}{c}\text { Peraturan Perundangan } \\
\text { (Regulation })\end{array}$ & $\begin{array}{c}\text { Perihal } \\
\text { (Substance) }\end{array}$ \\
\hline 1. & UUD 1945 pasal 33 ayat 3 & Penguasaan dan pemanfaatan Sumberdaya Alam \\
\hline 2. & UU No. 41/1999 & Kehutanan \\
\hline 3. & UU No.7/2004 & Sumber Daya Air \\
\hline 4. & UU No 19/2004 & $\begin{array}{l}\text { Penetapan Peraturan Pemerintah Pengganti } \\
\text { Undang-Undang Nomor } 1 \text { Tahun } 2004 \text { Tentang } \\
\text { Perubahan Atas Undang-Undang Nomor } 41 \\
\text { Tahun } 1999 \text { Tentang Kehutanan menjadi } \\
\text { Undang-Undang }\end{array}$ \\
\hline 5. & UU No. 32/2004 & Pemerintahan Daerah \\
\hline 6. & UU No. 33/2004 & $\begin{array}{l}\text { Perimbangan Keuangan antara Pemerintah Pusat } \\
\text { dan Pemerintah Daerah }\end{array}$ \\
\hline 7. & PP No. 62/1998 & $\begin{array}{l}\text { Penyerahan sebagian urusan pemerintahan di } \\
\text { bidang kehutanan kepada daerah }\end{array}$ \\
\hline 8. & PP. No. 68/1998 & $\begin{array}{l}\text { Kawasan suaka alam dan kawasan pelestarian } \\
\text { alam }\end{array}$ \\
\hline 9. & PP No. 25/2000 & Kewenangan Propinsi dalam Otonomi Daerah \\
\hline 10. & PP No. 34/2002 & $\begin{array}{l}\text { Tata Hutan dan Penyusunan Rencana } \\
\text { Pengelolaan Hutan Pemanfaatan Hutan dan } \\
\text { Penggunaan Kawasan Hutan }\end{array}$ \\
\hline 11. & PP No 63/2002 & Hutan Kota \\
\hline 12. & PP No. 44/2004 & Perencanaan Kehutanan \\
\hline 13. & PP No. 45/2004 & Perlindungan Hutan \\
\hline 14. & Keppres No 32/1990 & Pengelolaan kawasan lindung \\
\hline 15. & Keppres No 41/2004 & $\begin{array}{l}\text { Perizinan atau perjanjian di bidang pertambangan } \\
\text { yang berada di kawasan hutan }\end{array}$ \\
\hline 16. & Kepmenhut No. 20/2001 & $\begin{array}{l}\text { Pola umum dan standar serta kriteria rehabilitasi } \\
\text { hutan dan lahan }\end{array}$ \\
\hline 17. & Kepmenhut No. 70/2001 & $\begin{array}{l}\text { Penetapan kawasan hutan, perubahan status dan } \\
\text { fungsi kawasan hutan }\end{array}$ \\
\hline 18 & $\begin{array}{l}\text { Kepmenhutbun No. } \\
146 / \text { Kpts-II/1999 }\end{array}$ & $\begin{array}{l}\text { Pedoman Reklamasi Bekas Tambang dalam } \\
\text { Kawasan Hutan }\end{array}$ \\
\hline 19. & $\begin{array}{l}\text { Kepmenhut No. } \\
\text { 81/Menhut-VII/2004 }\end{array}$ & $\begin{array}{l}\text { Pembentukan Tim Terpadu dalam Rangka } \\
\text { Penyelesaian Izin Penggunaan Kawasan Hutan } \\
\text { Lindung untuk Kegiatan Pertambangan }\end{array}$ \\
\hline 20. & $\begin{array}{l}\text { Peraturan Menteri No. } \\
\text { P.12/2004 }\end{array}$ & Jaminan Reklamasi di Hutan Lindung \\
\hline
\end{tabular}

